\title{
Ärztinnen verschreiben seltener Antibiotika
}

Männliche, junge und ostdeutsche Ärzte verordnen die meisten Antibiotika. Eine Arbeitsgruppe am Robert Koch-Institut in Berlin hat Antworten von knapp 3500 Ärzten der Studie EVA (Einflüsse auf die ärztliche Verschreibung von Antibiotika in Deutschland) ausgewertet.

90\% der Ärzte gaben an, dass sie mindestens einmal pro Woche Antibiotika verordnen, $66 \%$ verschreiben diese täglich. Dabei ist der Anteil von Klinikern, die täglich mindestens eine antimikrobielle Therapie veranlassen, mit $69 \%$ nur wenig höher als bei den ambulant tätigen Kollegen
(63\%). Am häufigsten nutzen Urologen, HNO-Ärzte und Pädiater solche Therapien. Allgemeinmediziner und Internisten sind damit eher zurückhaltend.

Unterschiede gibt es auch zwischen den Geschlechtern: So gaben $72 \%$ der Ärzte, aber nur 56\% der Ärztinnen an, täglich Antibiotika zu verschreiben. Der Anteil von Ärzten mit täglichen Verordnungen war zudem bei den unter 30-Jährigen um 56\% höher als bei älteren Kollegen, und bei Ostdeutschen um $60 \%$ höher als bei Westdeutschen. Infection 2011; 39: 289-297

\section{WO SICH MRSA WOHLFÜHLT}

\section{Killerkeime in der Kitteltasche}

Sechs von zehn Arztkitteln beherbergen pathogene Keime, hat eine Studie ergeben, in der Abstriche von den Bauchpartien, den Ärmelenden und den Kitteltaschen genommen worden waren. Gefunden wurden auch multiresistente Erreger wie z. B. Methicillin-resistente Staphylokokken (MRSA). An der Studie hatten sich 75 Krankenschwestern und 60 Ärzte beteiligt. Bei 63\% (Schwestern 65\%, Ärzte 60\%) war mindestens ein Abstrich positiv auf potenziell pathogene Keime. Als einziger Risiko- faktor konnte die Häufigkeit des Kittelwechsels dingfest gemacht werden. „Die hohe Prävalenz kontaminierter Arbeitskleidung rührt womöglich von mangelnder Handhygiene her", meinen die Mikrobiologen. Resistente Keime fanden sich nämlich vor allem in den Taschen und an den Ärmelenden. Am J Infect Control 2011; 39: 555-9.

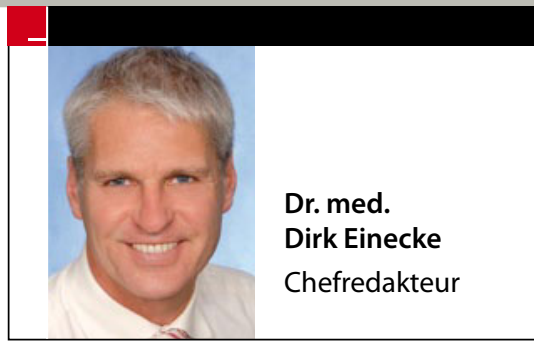

INFEKTIOLOGIE

\section{Vor der Darm-Op. gezielt auf Keimjagd gehen?}

Weniger postoperative Infektionen, weniger Anastomoseninsuffizienzen - so das Fazit einer Studie niederländischer Chirurgen. Sie hatten bei gastrointestinalen Eingriffen ein Verfahren zur perioperativen Elimination von Darmkeimen ausprobiert, das sie nun zur Nachahmung empfehlen. An der Studie waren 289 Patienten beteiligt, die einem elektiven Eingriff am Gastrointestinaltrakt entgegensahen. 143 von ihnen erhielten zusätzlich zur antibiotischen Standardprophylaxe

eine perioperative selektive Dekontamination des Darmtrakts (SDD), 146 wurden mit Scheinmedikamenten versorgt. 19,6\% der Patienten der SDD- und 30,8\% der Placebogruppe erlitten postoperative Infektionen. In sekundären Endpunkten wie Aufenthaltsdauer in der Klinik oder Mortalität ergaben sich keine statistisch erheblichen Differenzen zwischen den Gruppen. BrJSurg 2011; 98: 1365-1372

\section{UROLOGIE}

\section{Testosteronmangel schuld an Nykturie?}

Wenn Männer im Alter von über 40 nachts häufig zur Toilette müssen, könnte das auch an einem Mangel an Testosteron liegen. In einer aktuellen Studie litten Männer mit einem hohen Serumspiegel des Hormons nur halb so oft an Nykturie wie Altersgenossen mit niedrigen Werten. In der Studie bestimmten Urologen aus Taipeh die Sexualhormonspiegel bei 509 Männern im Alter von 40 bis 80 Jahren (Durch- schnittsalter 58 Jahre). Wurden gleichaltrige Männer untersucht, so stellte sich heraus, dass Männer mit hohen Serum-Testosteronwerten deutlich seltener nachts zur Toilette mussten als Männer mit niedrigen Werten: Im Quartil mit den höchsten Testosteronwerten war die Rate für eine Nykturie um $44 \%$ niedriger als im Quartil mit den niedrigsten Werten

Urology 2011; 78: 631-635



